\title{
Determination of Ganciclovir in Plasma of Newborns with Congenital CMV Infection
}

\author{
Laneri Sonia $^{1}$, Padula Cristina ${ }^{2}$, Buffolano Wilma ${ }^{3}$, Santi Patrizia ${ }^{2}$ and Dini Irene ${ }^{* 1}$ \\ ${ }^{1}$ Department of Pharmacy, Italy \\ ${ }^{2}$ Department of Food and Drug, Italy \\ ${ }^{3}$ Department of Pediatrics, Perinatal Infection Unit, Italy \\ *Corresponding author: Dini Irene, Via Domenico Montesano 49, Napoli 80131, Italy
}

\begin{tabular}{|c|c|}
\hline ARTICLE INFO & ABSTRACT \\
\hline $\begin{array}{l}\text { Received: 幽 May 15, } 2019 \\
\text { Published: 幽 May 22, } 2019\end{array}$ & $\begin{array}{l}\text { Infections caused by human cytomegalovirus are important causes of fetal and neo- } \\
\text { natal morbidity and mortality. Ganciclovir ([(9-(1,3-dihydroxy-2- propoxymethyl) gua- } \\
\text { nine, GCV) is a synthetic acyclic nucleoside which has shown activity against Cytomega- }\end{array}$ \\
\hline $\begin{array}{l}\text { Citation: Laneri S, Padula C, Buffolano W, } \\
\text { Santi P, Dini I. Determination of Ganciclo- } \\
\text { vir in Plasma of Newborns with Congen- } \\
\text { ital CMV Infection. Biomed J Sci \& Tech }\end{array}$ & $\begin{array}{l}\text { as neutropenia and leukopenia, thus drug monitoring is needed, especially in the case of } \\
\text { newborns. The aim of the work is to develop and validate an HPLC method for the quan- } \\
\text { tification of GCV in plasma. }\end{array}$ \\
\hline Res 18(2)-2019. BJSTR. MS.ID.003122. & Abbreviations: GCV: Ganciclovir; VGCV: Valganciclovir; HPLC: High-Performance Liquid \\
\hline $\begin{array}{l}\text { Keywords: Ganciclovir; HPLC-UV; Ana- } \\
\text { lytic Method }\end{array}$ & $\begin{array}{l}\text { Chromatography; RT: Retention Time; AUC: Area Under The Concentration Time Curve; } \\
\text { LLOQ: Lower Limit Of Quantifications; LLOD: Lower Limit Of Detection; SD: Standard } \\
\text { Deviation; RE: Relative Error; CV: Coefficient Of Variation }\end{array}$ \\
\hline
\end{tabular}

\section{Introduction}

The transmission of cytomegalovirus (CMV) to the fetus is a result of maternal viremia and transplacental infection often maternal CMV infections are subclinical. Mortality in symptomatic infants is about $10 \%$. Surviving newborns can contract mental retardation and other neurologic deficits $[1,2]$. The treatment of congenitally cytomegalovirus infected neonates involves the use of ganciclovir or its prodrug valganciclovir (GCV). Unfortunately, their use is limited by neutropenia, carcinogenicity, gonadal dysgenesis risks, development of viral resistance and drug-drug interactions $[3,4]$. Several strategies have been suggested to prevent high plasma ganciclovir concentrations and toxicity. Dosage reduction is recommended in patients with renal damage. Temporary discontinuation of an interacting medication, adjustment of dosages and careful monitoring of the patient is suggested to prevent any potential adverse effects of such interactions [5].

\section{Material and Method}

\section{Chemicals}

Ganciclovir and Trifluoroacetic acid (TFA) were purchased from Sigma Chemical Co. (St. Louis, MO). and 1-heptanesulfonic acid. Distilled water and perchloric acid were purchased from Sigma-Aldrich Chemical (St. Louis, MO, USA).

\section{Blood Samples Preparation}

Blood samples $(1.5 \mathrm{ml})$ were collected in gel separating tubes. The blood was then centrifuged for $5 \mathrm{~min}$ at $13000 \mathrm{rpm} .1 \mathrm{ml}$ of the serum thus obtained were added with $250 \mathrm{l}$ of TFA $20 \%$ and the suspension was then centrifuged at $13000 \mathrm{rpm}$ for $10 \mathrm{~min}$. Aliquots of deproteinated serum were stored at $-80^{\circ} \mathrm{C}$ until use.

\section{GCV Extraction}

$100 \mu \mathrm{l}$ of serum was added with $95 \mu \mathrm{l}$ of distilled water and $50 \mu \mathrm{l}$ of perchloric acid $7 \%$.

\section{Assay Application}

8 newborns with congenital CMV infection were treated with 15 $\mathrm{mg} / \mathrm{kg}$ of Valganciclovir (GCV prodrug) twice daily. Blood samples were collected before (TO) and after 2 hours (T1) of the morning administration.

\section{Chromatographic Conditions}

The chromatographic system consisted of an HPLC Jasco LCNet II/ADC (JASCO International Co., Ltd. Tokyo, Japan) with a 20 
$\mu \mathrm{L}$ Rheodyne 8125 injector (Rheodyne, Ronhert Park, CA, USA), an UV Detector UV “Jasco MD-2010 plus” (JASCO International Co., Ltd. Tokyo, Japan) ( $\sigma 254 \mathrm{~nm}$ ), and a reversed phase Jupiter C-18 5 $\sigma \mathrm{m}(150 \mathrm{x} 4.6 \mathrm{~mm})$ column (Phenomenex, California, USA). Using Distilled water as mobile phase and $1.2 \mathrm{ml} / \mathrm{min}$ flow rate.

\section{Results}

\section{Recovery of GCV}

Recovery of ganciclovir from the extraction process was calculated by using the next formula:

$$
\text { Recovery } \%=\frac{C_{1}}{C_{2} x 100}
$$

$\mathrm{C}^{1}=$ analyte concentration measured after addition

$\mathrm{C}^{2}=$ concentration of added standard

Results are reported in Table 1.

Table 1: Recovery.

\begin{tabular}{|c|c|c|}
\hline The Amount Added (mg) & Recovery (\%) & CV (\%) \\
\hline 0.23 & 110.51 & 1.87 \\
\hline 0.29 & 102.82 & 3.56 \\
\hline 0.33 & 104.97 & 2.39 \\
\hline
\end{tabular}

\section{GCV Stability}

GCV concentrations were stable in standard solutions after one month of storage at $4^{\circ} \mathrm{C}$, in plasma for at least $5 \mathrm{~h}$ at room temperature, in biological matrices when stored at $220^{\circ} \mathrm{C}$ for at least six months.

\section{Method Validation}

The method was validated, considering linearity, LLOD, LLOQ, precision and accuracy, according to European Medicines Agency guidelines Validation [6]. The method of constant addition was used for the construction of calibration curves Figure 1.

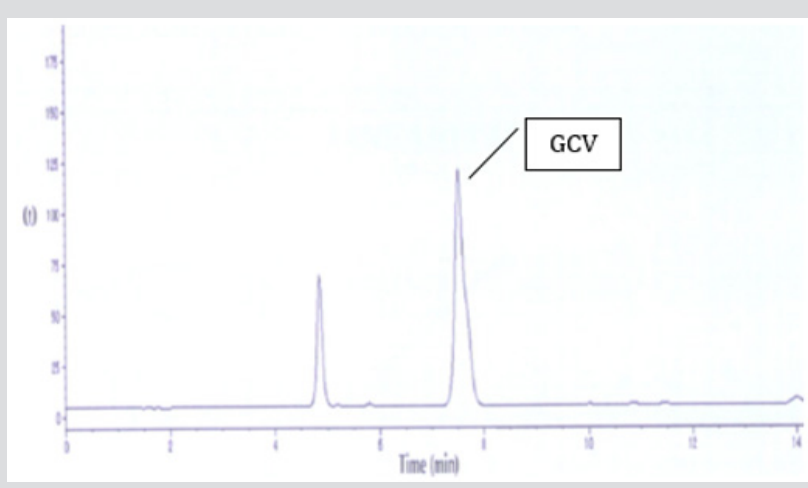

Figure 1: Chromatogram of blood samples collected after 2 hours of treatment with Valganciclovir.

\section{Method Selectivity}

The selectivity of the assay was defined by analysis of blank plasma, with and without internal standard. There are no interfering peaks present at the retention time for GCV peaks.

\section{Method Linearity}

The correlation coefficient of the linear regression was reported in Figure 2.

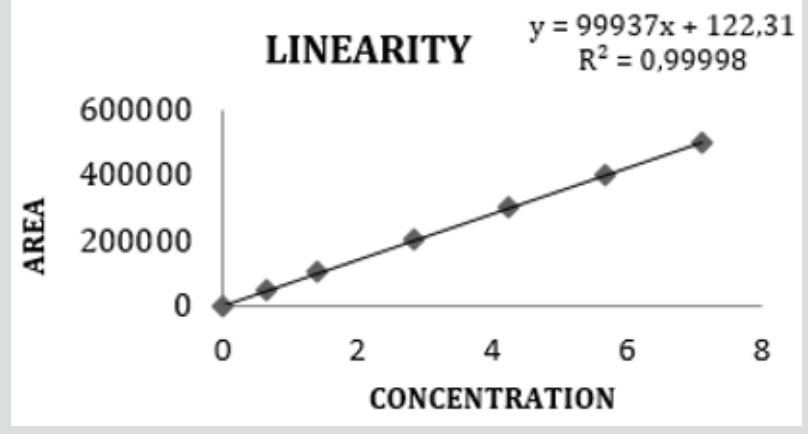

Figure 2: Linearity of the assay.

\section{Method Sensitivity}

The method detection limit was tested by repeated analysis of blank samples.

The detection limits were determined as the concentration giving a peak height three times the noise background

Lower limit of Detection (LLOD) $=3,3 \sigma / \mathrm{S}=0,021 \mu \mathrm{g} / \mathrm{mL}$

Lower Limit of Quantitation (LLOQ) $=10 \sigma / \mathrm{S}=0,065 \mu \mathrm{g} / \mathrm{mL}$

$\sigma=$ DS of the y intercept of regression line

$\mathrm{S}=$ slope of regression line

The quantitation limit of an individual analytical procedure is the lowest amount of analyte in a sample which can be quantitatively determined with suitable precision and accuracy. LLOQ $(0.065 \mu \mathrm{g} /$ $\mathrm{ml})$, was $>10$

\section{Method Accuracy}

The accuracy of the method was tested by relative error calculation. The accuracy values in intra-day variation studies at low, medium and high concentrations of GCV in plasma were within acceptable limits $(\mathrm{n}=5)$ Table 2.

Table 2: Relative error \& Relative standard deviation of regression line slope.

\begin{tabular}{|c|c|c|c|}
\hline Nominal Value $(\mu \mathbf{g} / \mathbf{M L})$ & Fitted Value $(\mu \mathbf{g} / \mathbf{M L})$ & RE\% & RSD $\%$ \\
\hline 0.1 & $0.10 \pm 0.01$ & 8.57 & 11.4 \\
\hline 0.5 & $0.51 \pm 0.02$ & 3.39 & 3.35 \\
\hline 1 & $1.00 \pm 0.02$ & 1.15 & 1.83 \\
\hline 2 & $1.98 \pm 0.02$ & 0.96 & 0.87 \\
\hline 5 & $5.01 \pm 0.05$ & 0.69 & 0.92 \\
\hline
\end{tabular}

Acceptable limits: $<15 \%$

\section{Method Precision}

The precision of the method was expressed by the coefficient of variation of intra- and inter-day variations of the assay under 
the same operating conditions. The acceptance criterion was set at 15\% Table 3.

Table 3: Intra and Inter-day variability and stability.

\begin{tabular}{|c|c|c|}
\hline Conditions & 24 Hours & 7 Days \\
\hline Room temperature & 1.17 & 3.05 \\
\hline $4^{\circ} \mathrm{C}$ & 3.28 & 6.39 \\
\hline$-20^{\circ} \mathrm{C}$ & 0.22 & 18.36 \\
\hline
\end{tabular}

\section{Method Applicability}

Applicability of the method was confirmed by analyzing samples from 8 newborns with congenital CMV infection treated with $15 \mathrm{mg} / \mathrm{kg}$ of Valganciclovir (GCV prodrug) twice daily. GCV concentration in blood samples collected before (TO) and after 2 hours (T1) of the morning administration are reported in Table 4.

Table 4: Assay application.

\begin{tabular}{|c|c|c|}
\hline Subject & $\mathbf{T}_{\mathbf{0}}(\mathbf{M g} / \mathbf{M l})$ & $\mathbf{T}_{\mathbf{1}}(\mathbf{M g} / \mathbf{M l})$ \\
\hline A & $0.21 \pm 0.09$ & $0.87 \pm 0.06$ \\
\hline B & $0.42 \pm 0.00$ & $1.04 \pm 0.10$ \\
\hline C & $0.28 \pm 0.02$ & $1.98 \pm 0.19$ \\
\hline D & $0.21 \pm 0.13$ & $2.04 \pm 0.13$ \\
\hline E & $0.11 \pm 0.02$ & $1.99 \pm 0.02$ \\
\hline F & $0.06 \pm 0.06$ & $2.00 \pm 0.77$ \\
\hline G & $0.35 \pm 0.37$ & $2.70 \pm 0.03$ \\
\hline H & $0.01 \pm 0.01$ & $1.94 \pm 0.10$ \\
\hline
\end{tabular}

The present HPLC method for the determination of GCV was useful for the therapeutic monitoring of antiviral medication.

\section{Discussion}

Amperometry detection [7], fluorescence detection, ionpairing agents [8,9], and UV detection [10-13], are general used to determine GCV. The difficult to detect GCV in newborn plasma are small volume of plasma available and little GCV concentration. The new analytical method developed was validated according to European Medicines Agency guidelines Validation. For the validation of the extraction procedures, samples of blank serum were spiked with known amounts of GCV. The recovery was determined by computing the ratio of the amount extracted from spiked samples to the amount added, determined by the injection of spiked solution. Ganciclovir was completely recovered during the extraction. Good ability to obtain results directly proportional to the concentration of analyte (not more than some number close to 1 ), fine detection limit, high precision demonstrated by very good intra- and inter-day repeatability (mean recoveries were near $100 \%$ and $\%$ RSD values were low) make this method a useful tool for the therapeutic monitoring of GCV medication. Applicability of the method was confirmed by analyzing samples from 8 newborns with congenital CMV infection treated with $15 \mathrm{mg} / \mathrm{kg}$ of Valganciclovir (GCV prodrug) twice daily.

\section{Conclusion}

The analytical method developed and validated is rapid and controllable in quality simple. The method showed high resolution, high sensitivity, good linearity, precision, accuracy and sensitivity. The inter-day variability is very low, and samples are stable in the condition tested up to 7 days. The recovery of GCV gave rise to a satisfactory recovery, thus avoiding the use of internal standards. Comparing our method to other proposed in the literature, it determines the GCV in smaller plasma concentrations, and is less expensive as it use a smaller variety of solvents. Results obtained in this study demonstrate its usefulness for therapeutic monitoring.

\section{References}

1. Padula C, Sartori F, Marra F, Santi P (2005) The influence of iontophoresis on acyclovir transport and accumulation in rabbit ear skin. Pharm Res 22 (9): 1519-1524.

2. Ornoy A, Diav-Citrin O (2006) Fetal effects of primary and secondary cytomegalovirus infection in pregnancy. Reprod Toxicol 21(4): 399-409.

3. Steininger C (2007) Novel therapies for cytomegalovirus. Recent Pat Antiinfect Drug Discov 2(1): 53 -57.

4. Wiltshire H, Paya CV, Pescovitz MD, Humar A, Dominguez E, et al. (2005) Pharmacodynamics of oral ganciclovir and valganciclovir in solid organ transplant recipients. Transplantation 79(11): 1477-1483.

5. Jacobsen T, Sifontis N (2010) Drug interactions and toxicities associated with the anti-viral management of cytomegalovirus infection. Am J Health Syst Pharm 67(17): 1417-1425.

6. (2008) European Medicines Agency, EMEA /CHMP /EWP /531305 / 2008, Conceptpaper / recommendations on the need for a guideline on the validation of bioanalytical methods.

7. Kishino S, Takekuma Y, Sugawara M, Furukawa H, Todo S, et al. (2002) Liquid chromatographic method for the determination of ganciclovir and/or acyclovir in human plasma using pulsed amperometric detection. J Chromatogr B 780(2): 289-294.

8. Perrottet N, Beguin A, Meylan P, Pascual M, Manuel O, et al. (2007) Determination of acyclovir and ganciclovir in human plasma by liquid chromatography-spectrofluorimetric detection and stability studies in blood samples J. Chromatogr B 852(1-2): 420-429.

9. Dao YJ, Jiao Z, Zhong MK (2008) Simultaneous determination of acyclovir, ganciclovir, and penciclovir in human plasma by high-performance liquid chromatography with fluorescence detection. J Chromatogr B 867(2): 270-216.

10. Cociglio M, Peyriere H, Hillaire-Buys D, Alric R (1998) Application of a standardized coextractive clean up procedure to routine highperformance liquid chromatography assays of teicoplanin and ganciclovir in plasma. J Chromatogr B 705(1): 79-85.

11. Teshima D, Otsubo K, Yoshida T, Ito Y, Oishi R, et al. (2003) A simple and simultaneous determination of acyclovir and ganciclovir in human plasma by high-performance liquid chromatography. Biomed Chromatogr 17(8): 500-503.

12. Page T, Sherwood C, Connor JD, Tarnowski T (1996) Simple reversed phase high -performance liquid chromatography quantitation of ganciclovir in human serum and urine. J Chromatogr B 675: 342-346.

13. Merodio M, Campanero MA, Mirshahi T, Mirshahi M, Irache JM, et al. (2000) Development of a sensitive method for the determination of ganciclovir by reversed-phase high-performance liquid chromatography. J Chromatogr A 870(1-2): 159-167. 


\section{ISSN: 2574-1241}

DOI: 10.26717/BJSTR.2019.18.003122

Dini Irene. Biomed J Sci \& Tech Res

(c) (P) This work is licensed under Creative

Submission Link: https://biomedres.us/submit-manuscript.php

$\begin{array}{ll}\text { BIOMEDICAL } & \text { Assets of Publishing with us } \\ \text { RESEARCHES } & \text { Global archiving of articles } \\ \text { - Immediate, unrestricted online access }\end{array}$

